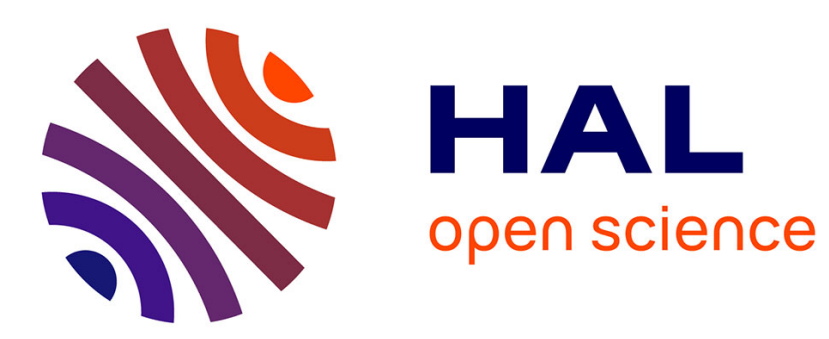

\title{
Venting of gases by convective clouds
}

Andrea Flossmann, Wolfram Wobrock

\section{To cite this version:}

Andrea Flossmann, Wolfram Wobrock. Venting of gases by convective clouds. Journal of Geophysical Research: Atmospheres, 1996, 101 (D13), pp.18639 - 18649. 10.1029/96JD01581 . hal-01905847

\section{HAL Id: hal-01905847 https://hal.uca.fr/hal-01905847}

Submitted on 6 Feb 2021

HAL is a multi-disciplinary open access archive for the deposit and dissemination of scientific research documents, whether they are published or not. The documents may come from teaching and research institutions in France or abroad, or from public or private research centers.
L'archive ouverte pluridisciplinaire HAL, est destinée au dépôt et à la diffusion de documents scientifiques de niveau recherche, publiés ou non, émanant des établissements d'enseignement et de recherche français ou étrangers, des laboratoires publics ou privés. 


\title{
Venting of gases by convective clouds
}

\author{
Andrea I. Flossmann and Wolfram Wobrock \\ Laboratoire de Météorologie Physique, Université Blaise Pascal, CNRS, OPGC, Aubière, France
}

\begin{abstract}
A two-dimensional dynamic model with spectral microphysics and a spectral treatment of aerosol particle and gas scavenging (DESCAM) was used to estimate the transport of gases from the marine boundary layer to the free troposphere by a mediumsized warm precipitating convective cloud. In the simulation, three gases were considered, covering a range of Henry's law constants: an inert tracer, $\mathrm{SO}_{2}$, and $\mathrm{H}_{2} \mathrm{O}_{2} . \mathrm{SO}_{2}$ was also used as the inert tracer by artificially suppressing any interaction with the cloud drops. The horizontal and vertical fluxes, their vertical means and the transport across the cloud boundaries were studied. It was calculated that for $\mathrm{SO}_{2}$ as an inert tracer $37 \mathrm{~kg}$, for $\mathrm{SO}_{2}$ as a scavenged gas $34 \mathrm{~kg}$, and for $\mathrm{H}_{2} \mathrm{O}_{2} 12 \mathrm{~kg}$ were transported from the marine boundary layer across cloud base to the free troposphere for an estimated three-dimensional cloud. This represents a depletion of the marine boundary layer in the vicinity of the cloud by about $60 \%$. After about half an hour of cloud life time, however, only $75 \%$ of the $\mathrm{SO}_{2}$ and only $30 \%$ of the $\mathrm{H}_{2} \mathrm{O}_{2}$ transported aloft still existed in the cloudy air. These residual gases could eventually participate in a long range transport if the cloud would dissipate. The rest had been scavenged by the cloud.
\end{abstract}

\section{Introduction}

Convective clouds are important features in determining our weather and climate. Apart from their radiative properties they have a strong dynamic and thermodynamic effect; that is, they redistribute vertically temperature and moisture and consequently reduce the instability of the atmosphere [e.g., Emanuel, 1994]. Coupled to these convective heat and water mass fluxes is the transport of other species to be found in the air. This transport is known to be an essential factor in the redistribution of atmospheric trace components.

Numerous atmospheric pollutants have their sources (natural or anthropogenic) at Earth's surface [Seinfeld, 1986]. There they are emitted and then distributed evenly in the well-mixed boundary layer. As long-range horizontal transport in the boundary layer is rather limited and the life times of some of the species are only of the order of a few days (e.g., the lifetime of gaseous $\mathrm{NO}_{x}$ is estimated to be in the range of 1-4 days, following Seinfeld [1986]), the species would stay close to the source in the absence of vertical transport. However, it has been argued that convection would provide an efficient means of transporting these chemical species from the boundary layer to the free troposphere. This process is called "cloud venting" [Ching, 1982; Cotton et al., 1995]. Owing to this transport of gaseous matter and aerosols from the boundary layer to the free troposphere, the pollutants can also participate in the long range transport, which takes predominantly place in these higher altitudes. There they can sometimes also experience longer residence times due to the changed temperatures and participate in the free tropospheric chemistry.

The effect of cloud venting has been shown to be important by numerous authors for different clouds and cloud systems (e.g., by Chatfield and Crutzen [1984], Ferek et al. [1986], and Lelieveld and Crutzen [1994] for dimethylsulfide and ozone). A comprehensive review of observational and modeling studies

Copyright 1996 by the American Geophysical Union.

Paper number 96JD01581.

0148-0227/96/96JD-01581\$09.00 on cloud venting by a wide variety of cloud types ranging from ordinary cumuli to ordinary cumulonimbi, mesoscale convective systems, and tropical and extratropical cyclones has been given by Cotton et al. [1995].

The present paper aims to improve the understanding of cloud venting by quantifying the advective fluxes of trace gases from a detailed cloud-resolving model. The role of the convective cloud is studied by calculating the mass transport of the trace gases across all cloud boundaries and from the marine boundary layer (MBL) to the free troposphere. Furthermore, the study supports the development of a parameterization of cloud venting for larger-scale models by providing mean flux profiles of trace gases of different solubilities through the cloud and estimating the net effect of clouds on the redistribution of trace gases in the lower free atmosphere.

In order to quantify the amount of cloud venting from a detailed cloud resolving model we have applied our detailed scavenging and microphysical (DESCAM) model [e.g., Flossmann et al., 1985; Flossmann and Pruppacher, 1988; Flossmann, 1994] embedded in the two-dimensional dynamics provided by the model of Clark and coworkers [e.g., Clark, 1977, 1979; Clark and Gall, 1982; Clark and Farley, 1984; Hall, 1980] to a moderate warm convective cloud developing on GATE day 261. The sounding is displayed in Figure 1. The Global Atmospheric Research Program Atlantic Tropical Experiment (GATE) campaign was performed in 1974 off the coast of Africa in the intertropical convergence zone (ITCZ). The measurements showed that the well-mixed boundary layer had a depth of about $500 \mathrm{~m}$ [Warner et al., 1979; Nicholls and LeMone, 1980]. Above, there was a moist layer reaching about $2.2 \mathrm{~km}$ capped by a stable layer where the air was very dry. Brümmer [1978] showed that this inversion layer was typical of an environment disturbed by previous convection and that these inversions normally did not persist for more than a couple of hours. Consequently, they would not inhibit the exchange of air masses between the moist layer and the higher troposphere.

We used this dynamical situation to study the transport of 


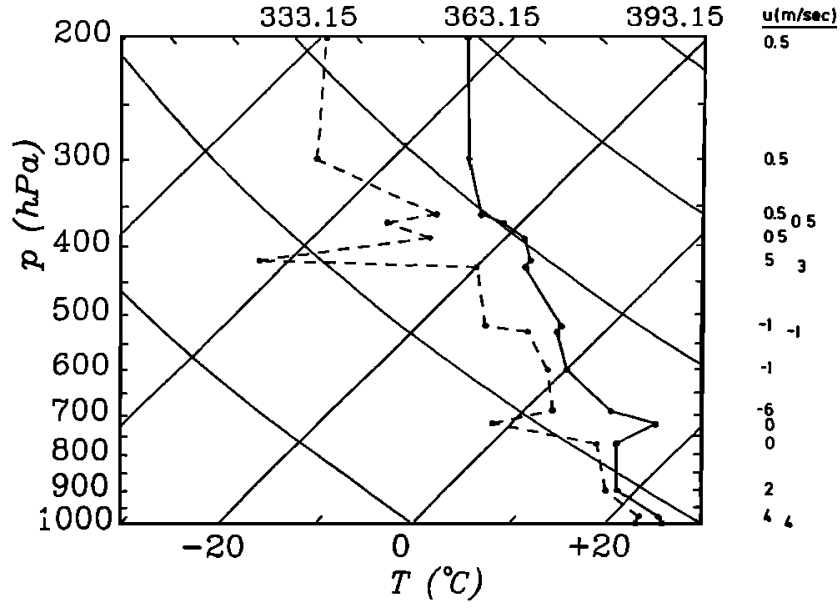

Figure 1. Sounding of GATE 261 as used in model calculation.

trace gases from the well-mixed boundary layer to the free troposphere by a moderate-sized convective cloud. As we can expect the amount of trace gases present in, and transported through, the cloudy air to be strongly influenced by the solubility of the considered trace gases, we choose to study the behavior of three different gases (inert tracer, $\mathrm{SO}_{2}$, and $\mathrm{H}_{2} \mathrm{O}_{2}$ ) covering the range of Henry constants commonly found in the atmosphere. We have used $\mathrm{SO}_{2}$ also as an inert tracer by artificially suppressing any uptake by the cloud drops. Even though this is an unrealistic scenario, it is nevertheless useful in two aspects. First, as $\mathrm{SO}_{2}$ is not interacting with the cloud, it can also be considered as a generic inert tracer; the results obtained apply to any inert tracer with a similar spatial distribution. Second, the run is useful as it allows a direct comparison with the case where $\mathrm{SO}_{2}$ is scavenged by the developing and evolving cloud drops. For the three gases considered, we calculated vertical and horizontal advective fluxes, mean advective fluxes, and the mass transport across the cloud boundaries. This enabled us to quantify the venting of pollutants by a convective cloud.

\section{Model Description}

As discussed in detail by Flossmann and Pruppacher [1988], the basic framework employed in the present study is a twodimensional slab-symmetric version of the three-dimensional model developed by Clark and coworkers [e.g., Clark, 1977, 1979; Clark and Gall, 1982; Clark and Farley, 1984; Hall, 1980]. DESCAM (i.e., the detailed scavenging and microphysical model) is discussed by Flossmann et al. [1985, 1987]. They treat the aerosol particles in a spectral form. Apart from dynamical processes, the number of particles of a certain size changes due to activation to drops, due to size changes resulting from humidity changes, and due to impaction scavenging by drops. The nucleated drops then grow by condensation or evaporate, collide and coalesce, and eventually break up. During their lifetime they further scavenge particles, and the scavenged pollutant mass is redistributed through the microphysical processes. The extension of this microphysical and scavenging model to the scavenging of two different types of aerosol particles (e.g., $\left(\mathrm{NH}_{4}\right)_{2} \mathrm{SO}_{4}$ and $\mathrm{NaCl}$ for marine air masses) is described by Flossmann [1991] and the inclusion of effects of gaseous $\mathrm{H}_{2} \mathrm{O}_{2}$ and $\mathrm{O}_{3}$ on the uptake and oxidation of $\mathrm{SO}_{2}$ was presented by Flossmann [1994]. Currently, the model contains prognostic equations for 11 distribution functions: the drop number density distribution function $f_{d}(m)$, the mass density distribution function $g_{\mathrm{APd},(\mathrm{NH} 4) 2 \mathrm{SO} 4}(m)$ and $g_{\mathrm{APd}, \mathrm{NaCl}}(m)$ for $\left(\mathrm{NH}_{4}\right)_{2} \mathrm{SO}_{4}$, and $\mathrm{NaCl}$ particles in the drops, respectively. In addition the mass density distribution functions $g_{\mathrm{Gd}, \mathrm{S}(4)}(m), g_{\mathrm{Gd}, \mathrm{S}(6)}(m)$, $g_{\mathrm{Gd}, \mathrm{H} 2 \mathrm{O} 2}(m)$, and $g_{\mathrm{Gd}, \mathrm{O} 3}(m)$, for the sulfur species $\mathrm{S}(4)$ and $\mathrm{S}(6)$, and $\mathrm{H}_{2} \mathrm{O}_{2}$ and $\mathrm{O}_{3}$ gas in the drops, respectively, are predicted with $m$ being the drop mass discretized in 57 radius size bins. The aerosol particle number density distribution functions $f_{\mathrm{APa},(\mathrm{NH}) 2 \mathrm{SO} 4}\left(m_{\mathrm{AP}}\right)$ and $f_{\mathrm{APa}, \mathrm{NaCl}}\left(m_{\mathrm{AP}}\right)$ for $\left(\mathrm{NH}_{4}\right)_{2} \mathrm{SO}_{4}$ and $\mathrm{NaCl}$ particles in the air and the mass density distribution functions $g_{\mathrm{APa},(\mathrm{NH} 4) 2 \mathrm{SO} 4}\left(m_{\mathrm{AP}}\right)$ and $g_{\mathrm{APa}, \mathrm{NaCl}}\left(m_{\mathrm{AP}}\right)$ for $\left(\mathrm{NH}_{4}\right)_{2} \mathrm{SO}_{4}$ and $\mathrm{NaCl}$ particles in the air, with $m_{\mathrm{AP}}$ being the aerosol particle mass discretized in 81 radius size bins are also predicted. For further details on the terms changing the density distribution functions, see Flossmann et al. [1985] and Flossmann [1994].

The time change of the gas $g_{\mathrm{Ga}}$ (in grams per cubic meter) which stands for the mass density of $\mathrm{SO}_{2}, \mathrm{H}_{2} \mathrm{O}_{2}$, and $\mathrm{O}_{3}$ in the air, i.e., $g_{\mathrm{Ga}, \mathrm{SO} 2}, g_{\mathrm{Ga}, \mathrm{H} 2 \mathrm{O} 2}$, and $g_{\mathrm{Ga}, \mathrm{O} 3}$ is described by

$$
\begin{aligned}
\frac{\partial g_{\mathrm{Ga}}}{\partial t}= & -\nabla \cdot\left(\mathbf{v} g_{\mathrm{Ga}}\right)+\nabla \cdot\left(K_{m} \nabla g_{\mathrm{Ga}}\right) \\
& -\left.\int_{0}^{\infty} \frac{\partial g_{\mathrm{Gd}}(m)}{\partial t}\right|_{\text {uptake }} d m .
\end{aligned}
$$

The first term on the right-hand side describes the advective transport and the second one the turbulent mixing using firstorder $\mathrm{K}$ theory with a turbulent eddy mixing coefficient from Smagorinsky [1963] and Lilly [1962] as described by Flossmann and Pruppacher [1988]. The last term represents the scavenging of the gases into the liquid phase where chemical reactions can occur. The treatment of this term is explained in detail by Flossmann [1994].

The model covered a domain of $10 \mathrm{~km}$ in the vertical and 20 $\mathrm{km}$ in the horizontal. The grid spacings were $\Delta z=200 \mathrm{~m}$ and $\Delta x=400 \mathrm{~m}$ resulting in $52 \times 52$ grid points. The time step was $\Delta t=5 \mathrm{~s}$.

\section{Analysis of the Data}

In the present paper we are interested in investigating the transport fluxes of gases into the cloud. Here, we confine ourselves to the study of $\mathrm{SO}_{2}$ and $\mathrm{H}_{2} \mathrm{O}_{2}$ and neglect the investigation of $\mathrm{O}_{3}$ which is simultaneously present at all times.

To minimize the amount of data to process, we only consider average fluxes over a time period of $100 \mathrm{~s}$ for the two remaining gases $\mathrm{SO}_{2}$ and $\mathrm{H}_{2} \mathrm{O}_{2}$. Consequently, the horizontal fluxes $F_{h}$ and the vertical fluxes $F_{v}$ were calculated as

$$
\begin{aligned}
& F_{h}=\frac{1}{n} \sum_{0}^{n} u g_{\mathrm{Ga}} \\
& F_{v}=\frac{1}{n} \sum_{0}^{n} w g_{\mathrm{Ga}} .
\end{aligned}
$$

Here, $u$ and $w$ are the horizontal and the vertical component of the 2-D velocity field $\mathrm{v}$, with $n=20$ and $\Delta t=5 \mathrm{~s}$ which results in an averaging time of $n \Delta t=100 \mathrm{~s}$. The fluxes in this calculation have the dimension of $\mathrm{g} \mathrm{m}^{-2} \mathrm{~s}^{-1}$ and are presented 
in Figures 3 and 4 which will be discussed in the section on model results.

To obtain from the fluxes the actual masses transported through the boundaries, we had to identify the location of the cloud boundary. This was done by checking if $q_{c}$, i.e., the amount of liquid water in the cloud drops smaller than $30 \mu \mathrm{m}$, is smaller than $10^{-4} \mathrm{~g} / \mathrm{kg}$ at one grid point and larger at the neighboring grid point. Then the common boundary between these two grid boxes is taken as the cloud boundary. (The value at the grid point represents the mean of its surrounding grid box.) For this calculation we did not choose the total liquid water $w_{\mathrm{L}}$ as this would mean a cloud base at Earth's surface in cases of rainfall.

Consequently, we checked the fluxes four times for the bottom, top, left, and right boundary of the cloud and calculated the total transport across the corresponding boundary

$$
T_{\text {boundary }}=\sum_{\mathbf{0}}^{L}(+/-) F_{h / v(\text { boundary })} \Delta l .
$$

Here, $L \Delta l$ is the length of the boundary with $\Delta l$ being $\Delta x=$ $400 \mathrm{~m}$ or $\Delta z=200 \mathrm{~m}$. The transport has the dimension of $\mathrm{g}$ $\mathrm{m}^{-1} \mathrm{~s}^{-1}$ and the signs (+/-) are adjusted such that a positive transport value always signifies a gain for the cloud and a negative transport value is a loss for the cloud. These quantities are given in Figure 2.

In order to obtain the total transport across each boundary the quantities are summarized over the entire $60 \mathrm{~min}$ of simulation time. These quantities are summarized in Table 2 as well as the total transport across the cloud boundaries, which is calculated as

$$
T^{\text {total }}=T_{\text {base }}^{\text {total }}+T_{\text {top }}^{\text {tolal }}+T_{\text {left }}^{\text {olal }}+T_{\text {right. }}^{\text {total }}
$$

All these total transport values have a dimension of $\mathrm{g} / \mathrm{m}$ as they pertain to a 2-D cloud, i.e., a slice of cloud having unit depth.

We have, however, attempted to crudely estimate the total transport through cloud base of a 3-D cloud as we think that these quantities are easier to use as the previously calculated values per unit depth. This requires giving the cloud a third dimension. For this purpose, we chose $5 \mathrm{~km}$, the approximate average length of cloud base during the time of the strongest transport. Consequently,

$$
T_{\text {base }}^{3-D, \text { toalal }}=T_{\text {base }}^{\text {tolal }} \cdot 5 \mathrm{~km}
$$

which gives the total estimated 3-D transport through cloud base in grams.

The summation of these fluxes through the cloud boundaries, however, includes some simplifications. One is that the stored values of the fluxes represent averages over $100 \mathrm{~s}$, implying that during this time the location of the cloud boundaries does not change dramatically. Typically, this is a valid assumption. A further simplification in our simulations of the transport across the cloud boundaries is the neglect of two processes which may also contribute to a net transport. The first one is the transport through turbulent mixing which is treated separately from the simple advection and is not included in the mass transfer calculations made. We argue here that the transport through turbulent eddy mixing into a convective cloud may contribute to the total transport; this process is dominated, however, by advection. Another process not considered is a complete evaporation of the liquid water at a given point on the cloud margin. This would put the values at the grid point immediately outside the cloud without this transfer being captured in the mass transfer calculations. However, considering the fact that this process works in both ways (i.e. for evaporation as well as condensation), we can expect the net effect to be small for our study.

\section{Initial Conditions}

The initialization of the present model is the same as that of Flossmann [1991, 1994] with the exception of the initial concentrations of $\mathrm{SO}_{2}$ and $\mathrm{H}_{2} \mathrm{O}_{2}$ : The sounding was taken at day 261 (September 18, 1974) of the GATE campaign at 1200 UT and is given in Figure 1. Our 2-D model domain was oriented north-south, as this was the main wind direction. In the lowest $2 \mathrm{~km}$, and above $6 \mathrm{~km}$ the wind was southerly, while in between the wind was northerly. The initial aerosol particle spectrum was assumed to be of maritime type consisting of a superposition of three lognormal distributions. The two small modes were assumed to consist of $\left(\mathrm{NH}_{4}\right)_{2} \mathrm{SO}_{4}$ particles, and the large mode was set to hold only $\mathrm{NaCl}$ particles. The particle spectra were assumed to decrease exponentially with height as practically no $\mathrm{NaCl}$ exists above $2.5 \mathrm{~km}$ (scale height of $1 \mathrm{~km}$ [cf. Flossmann, 1991]). The $\left(\mathrm{NH}_{4}\right)_{2} \mathrm{SO}_{4}$ particles were assumed to decrease with a scale height of $\mathbf{3} \mathbf{~ k m}$ as described by Flossmann [1991].

The $\mathrm{SO}_{2}, \mathrm{H}_{2} \mathrm{O}_{2}$, and $\mathrm{O}_{3}$ initial concentrations were assumed to $0.5 \mathrm{ppb}, 0.5 \mathrm{ppb}$, and $30 \mathrm{ppb}$, respectively, in agreement with marine observations [e.g., Cuong et al., 1974; Kok, 1980; Wolff et al. 1986; Winkler, 1988]. In order to calculate the transport of $\mathrm{SO}_{2}$ and $\mathrm{H}_{2} \mathrm{O}_{2}$ produced at the surface we prescribed constant values for $\mathrm{SO}_{2}$ and $\mathrm{H}_{2} \mathrm{O}_{2}$ in the first $400 \mathrm{~m}$ above ground (two grid levels), above which the concentrations were set to zero. The prescribed concentration of $\mathrm{O}_{3}$ was constant with height. In the first simulation (case 1) the uptake of $\mathrm{SO}_{2}$ and its oxidants into the liquid phase was purposely inhibited, thus considering $\mathrm{SO}_{2}$ as an inert tracer. In the second simulation (case 2), all three gases were scavenged by the cloud drops with $\mathrm{H}_{2} \mathrm{O}_{2}$ and $\mathrm{O}_{3}$ serving as oxidizing agents converting $\mathrm{S}(4)$ to $\mathrm{S}(6)$. This was done to be able to identify the role of cloud gas uptake for the vertical redistribution of atmospheric pollutants by convection.

The cloud was driven by a surface sensible and latent heat flux as a percentage of the incoming solar radiation. The method is described by Flossmann [1991].

\section{Model Results}

As mentioned above in the section on model initialization, we have used almost the same input parameters for the present model as those used for the investigation on aerosol particle and gas scavenging [Flossmann, 1991, 1994]. Thus the evolution of the dynamical and microphysical features is the same, and we shall only briefly summarize them and concentrate on the results of the flux calculations.

The simulations started at 1200 UT. After 26 min of model time a cloud had formed. After $14 \mathrm{~min}$ of cloud life time the first rain fell from cloud base, and after $19 \mathrm{~min}$ of cloud life time the first rain reached the ground. The rain lasted for about $25 \mathrm{~min}$, the last $10 \mathrm{~min}$ being only an insignificant drizzle (precipitation rate below $1 \mathrm{~mm} / \mathrm{h}$ ). Therefore we terminated the simulation after $60 \mathrm{~min}$. The dynamical and microphysical results compared quite well with observations made during that day [Flossmann, 1991, Table 2]. 

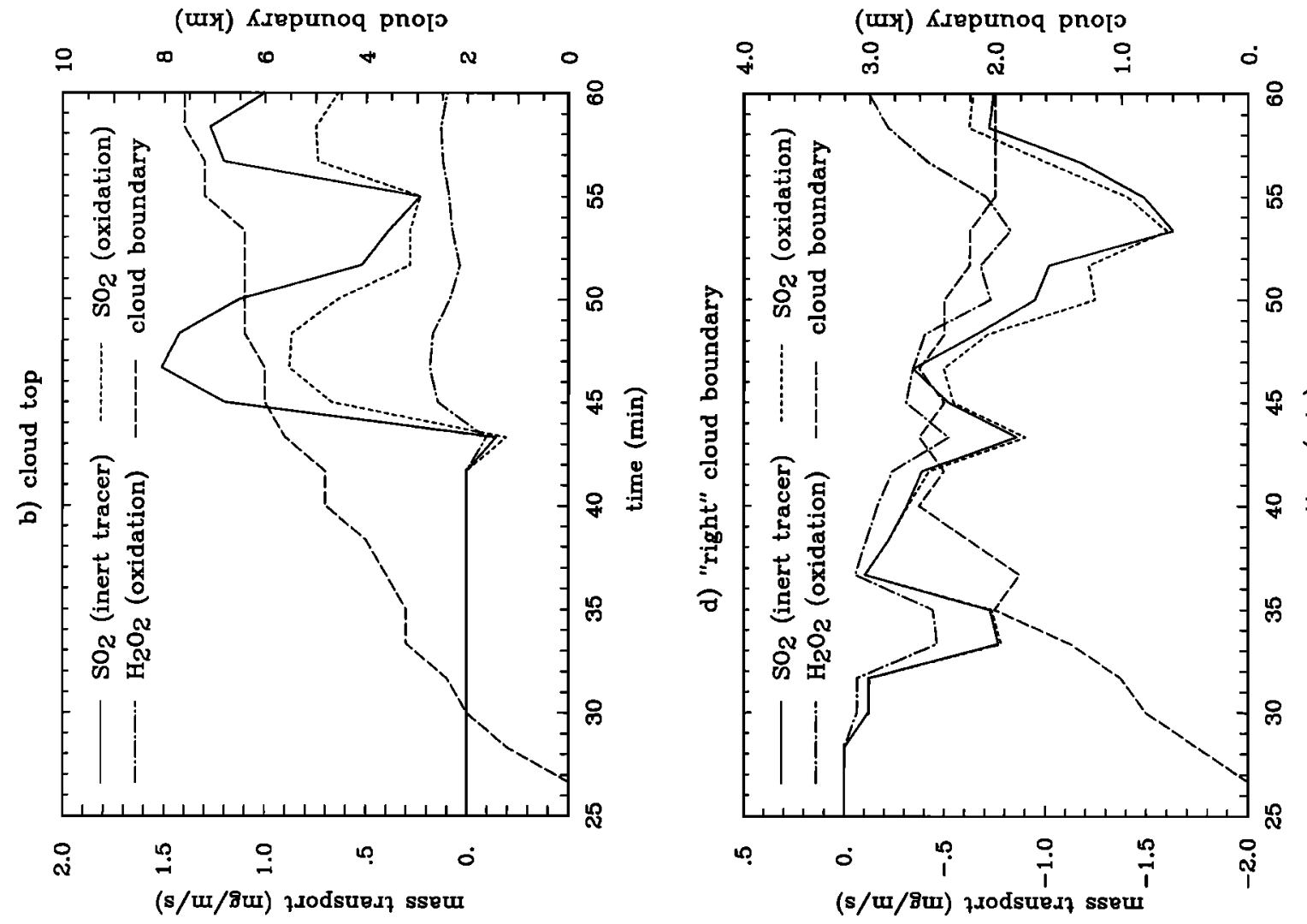

穴

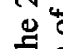

可

2

ะ
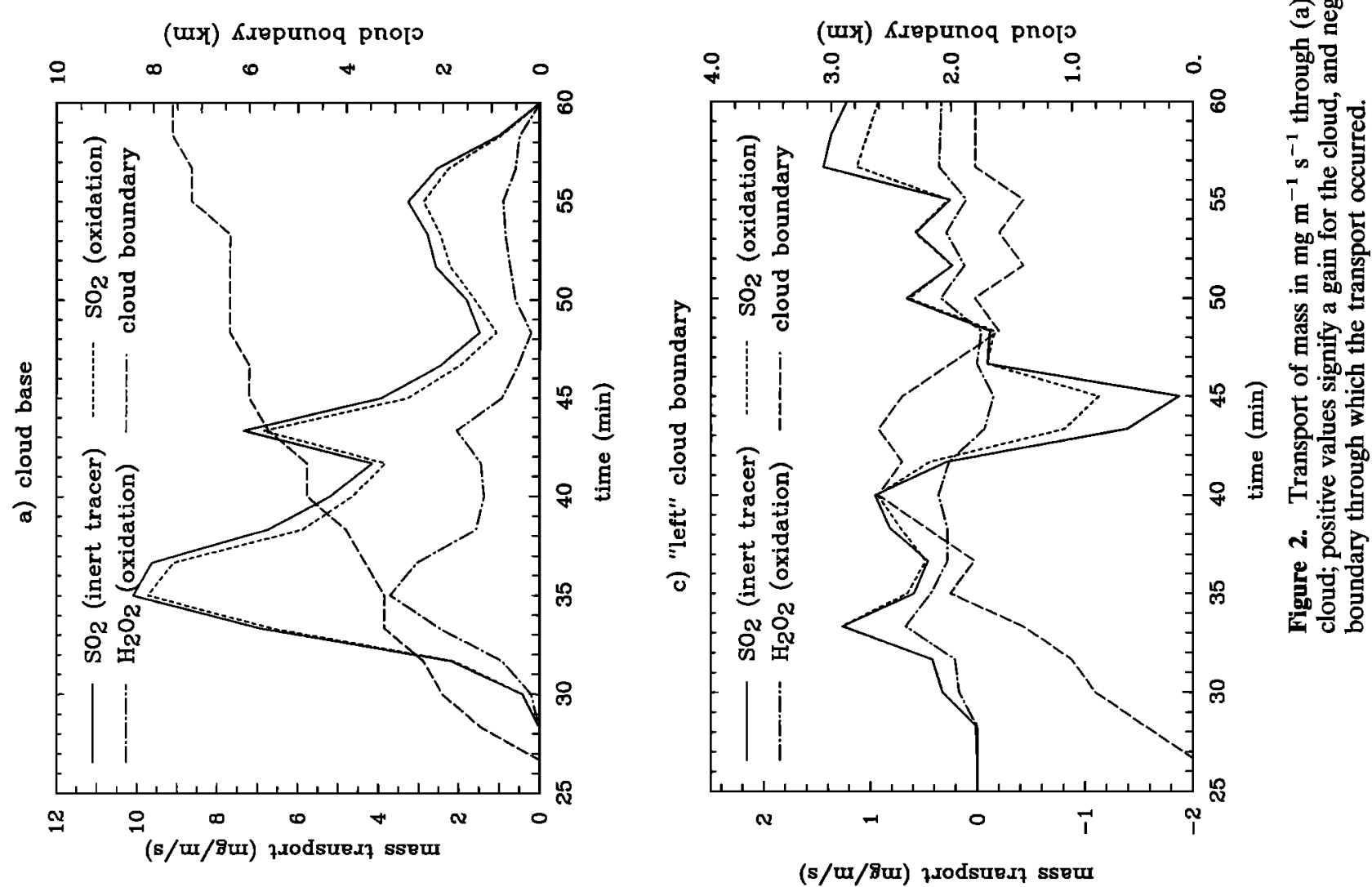

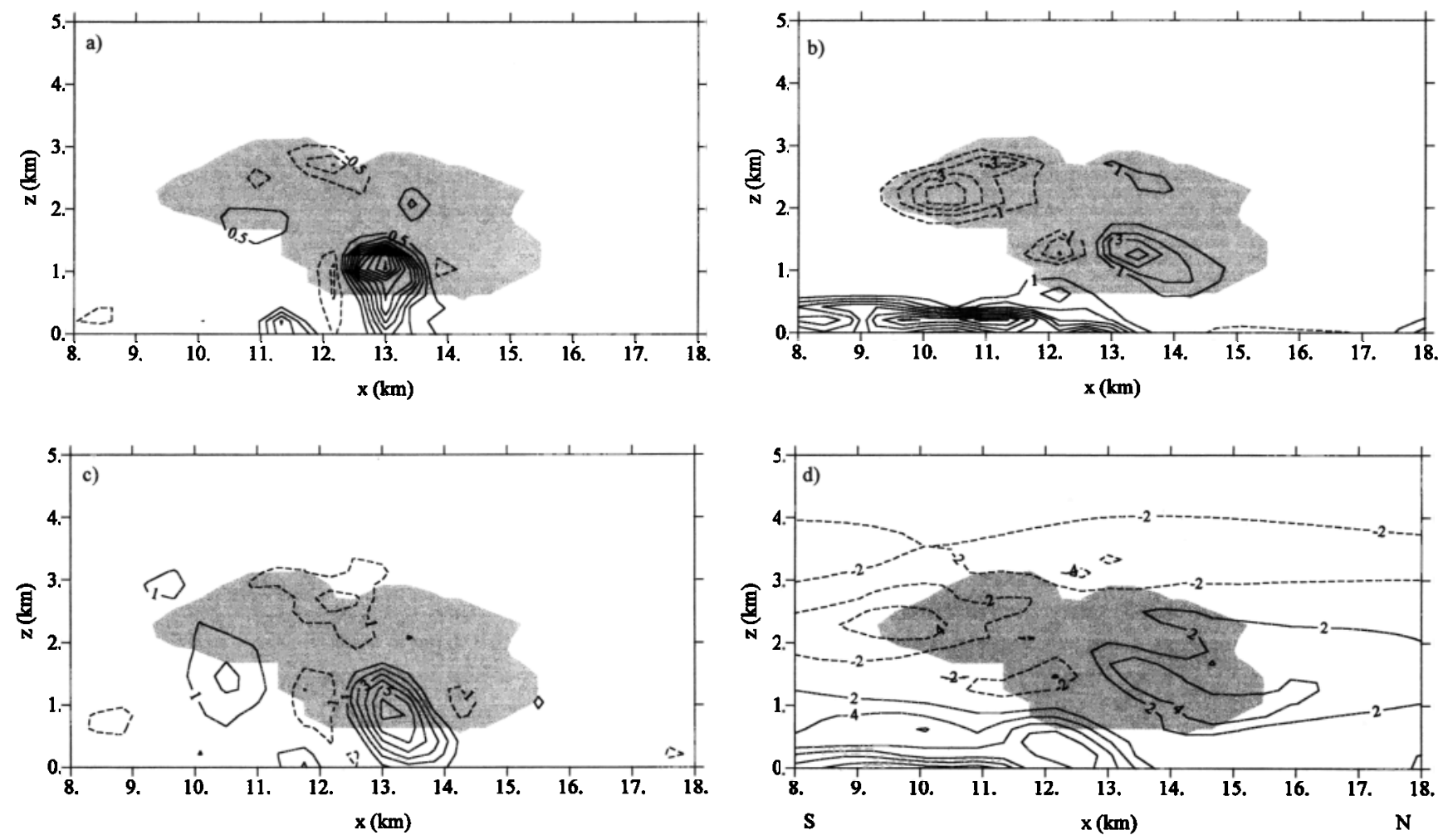

Figure 3. (a) Vertical flux of $\mathrm{SO}_{2}$, (b) horizontal flux of $\mathrm{SO}_{2}$ considered as an inert tracer in $\mu \mathrm{g} / \mathrm{m}^{2} / \mathrm{s},(\mathrm{c})$ vertical velocity, and (d) horizontal velocity in meters per second after $45 \mathrm{~min}$ of model time (19 min of cloud life time). In Figure 3a, solid lines signify mean upgoing fluxes, dashed lines signify downgoing fluxes, and contour spacing is $0.5 \mu \mathrm{g} \mathrm{m}^{-2} \mathrm{~s}^{-1}$. In Figure $3 \mathrm{~b}$, solid lines signify fluxes going to the right, dashed lines signify fluxes going to the left, and contour spacing is $1 \mu \mathrm{g} \mathrm{m}^{-2} \mathrm{~s}^{-1}$. In Figure $3 \mathrm{c}$, solid lines signify updrafts, dashed lines signify downdrafts, and contour spacing is $1 \mathrm{~m} / \mathrm{s}$. In Figure 3d, solid lines represent southerly flows (from left to right), dashed lines represent northerly flows (from right to left), and contour spacing is $2 \mathrm{~m} / \mathrm{s}$; the shaded area is the visible cloud $\left(q_{c}>10^{-4} \mathrm{~g} / \mathrm{kg}\right)$.

The results concerning the aerosol particle scavenging were the same as those of Flossmann [1991, 1993]. The results of the gas scavenging were slightly different from those presented by Flossmann [1994] due to the different initial conditions. They will, however, not be discussed here as our interest is the transport of pollutants from the marine boundary layer (MBL) to the free troposphere by a medium-sized convective cloud. Here we will focus on the major cell developing in the computational domain and neglect the secondary cells forming in the rightmost $7 \mathrm{~km}$ (see Figures 5 and 6).

The transport through the developing main cloud is illustrated in Figures 2-9 for the two cases considered. Figure 2 displays the transport through the four cloud boundaries which can be identified by a 2-D model: cloud base (Figure 2a), cloud top (Figure 2b), left (Figure 2c) and right (Figure 2d) boundary. In addition to the net transport of the gases through the cloud boundary the "length" of the associated cloud boundary is given by the long-dashed line in Figures $2 \mathrm{a}-2 \mathrm{~d}$. Here we have to point out that only in a $2-\mathrm{D}$ simulation the cloud has an artificial left and right boundary which pertains to the lateral entrainment and detrainment in Figures 3 and 4. The time evolution of the height of cloud base and cloud top is given in Table 1 together with some characteristic features of the cloud. In general, we can see from Figure 2 that at all times the time evolution of the three gaseos concentrations displayed shows the same qualitative behavior. Quantifying the mass transport across the four different boundaries considered in a 2-D sim- ulation, we can see that case 1 (solid line) shows the strongest transport, and the weakest transports are found for $\mathrm{H}_{2} \mathrm{O}_{2}$ (dash-dotted line). In the middle, we find $\mathrm{SO}_{2}$ with uptake into the liquid phase and subsequent oxidation processes considered. The difference between the curves for $\mathrm{SO}_{2}$ as a scavenged and oxidized gas and $\mathrm{H}_{2} \mathrm{O}_{2}$ results from two facts. The first is that $0.5 \mathrm{ppb}(\mathrm{v}) \mathrm{SO}_{2}$ and $0.5 \mathrm{ppb}(\mathrm{v}) \mathrm{H}_{2} \mathrm{O}_{2}$ give a higher mass concentration (about a factor of 2) for $\mathrm{SO}_{2}$ than for $\mathrm{H}_{2} \mathrm{O}_{2}$ (initial boundary layer mass concentrations are $1.4 \mu \mathrm{g} / \mathrm{m}^{3}$ for $\mathrm{SO}_{2}$ and $0.76 \mu \mathrm{g} / \mathrm{m}^{3}$ for $\mathrm{H}_{2} \mathrm{O}_{2}$ ). The second difference results from the fact that $\mathrm{H}_{2} \mathrm{O}_{2}$ is much more soluble than $\mathrm{SO}_{2}$ (the Henry's constants, dissociation constants and oxidation rates were taken from Seinfeld, 1986).

In Figure $2 \mathrm{a}$ we see that the transport through cloud base has its maximum around $35 \mathrm{~min}$ (i.e., $9 \mathrm{~min}$ of cloud life time) corresponding to the maximum in vertical wind speed (see Table 1). A second maximum appears at $45 \mathrm{~min}$ due to the fact that next to the original cloud a secondary cloud appears with its own updraft (see the vertical velocities in Figure 3a and Table 2 of Flossmann [1991] and in Figure 3c of this paper). This secondary cloud is contiguous with the first one, and we consider them as one large cell. As time proceeds, the total influx through cloud base decreases. This is caused by precipitation which develops between 35 and $40 \mathrm{~min}$, leaving the cloud base at $40 \mathrm{~min}$ and reaching the ground at $45 \mathrm{~min}$ of model time. This rain is coupled to a downdraft causing an outflow at cloud base, resulting in a net reduced inflow (com- 

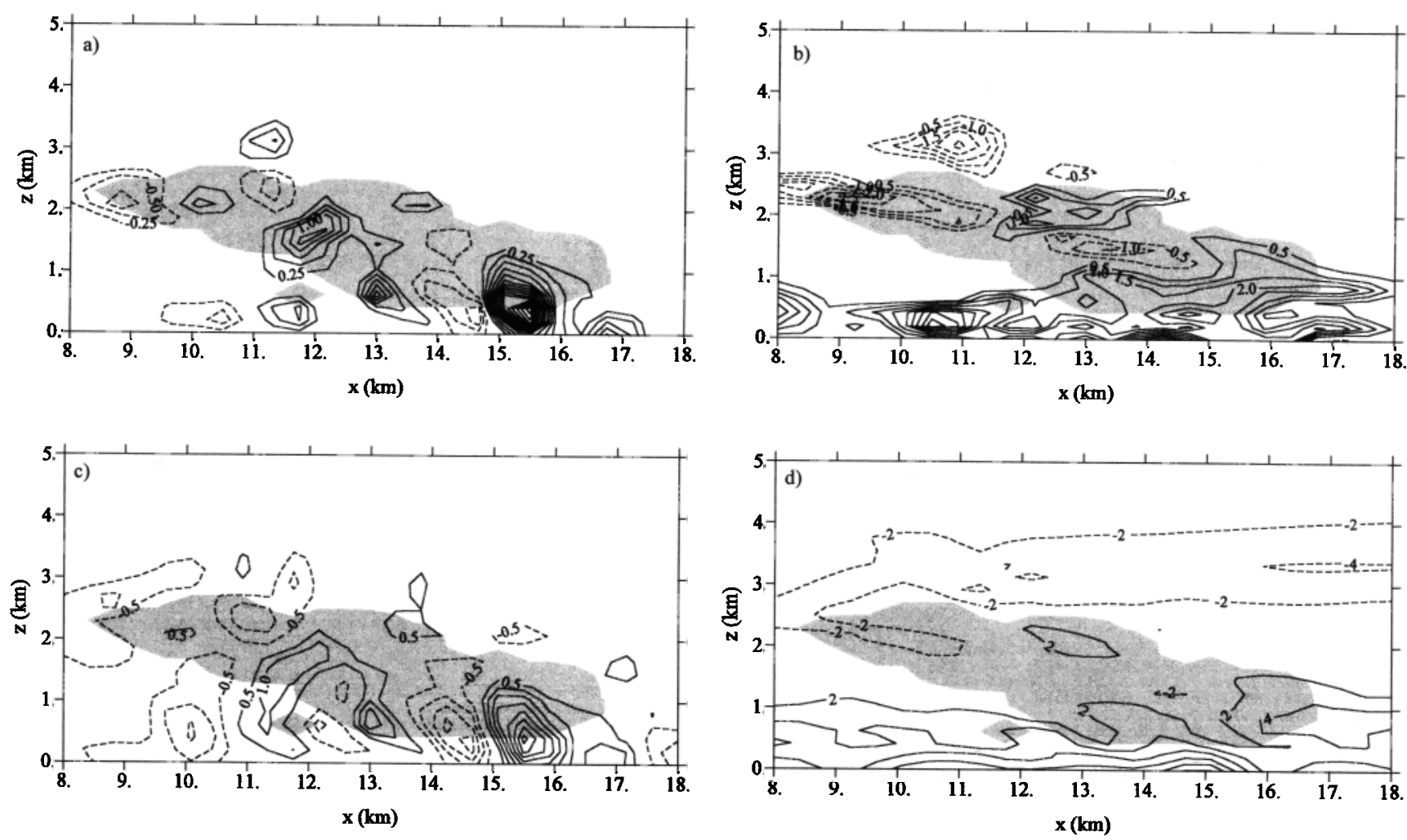

Figure 4. (a) Vertical flux of $\mathrm{SO}_{2}$, (b) horizontal flux of $\mathrm{SO}_{2}$ considered as an inert tracer in $\mu \mathrm{g} \mathrm{m}^{-2} \mathrm{~s}^{-1}$, (c) vertical velocity, and (d) horizontal velocity in meters per second after $55 \mathrm{~min}$ of model time (29 min of cloud life time). In Figure 4a, solid lines signify mean upgoing fluxes, dashed lines signify downgoing fluxes, and contour spacing is $0.25 \mu \mathrm{g} \mathrm{m}^{-2} \mathrm{~s}^{-1}$. In Figure $4 \mathrm{~b}$, solid lines signify fluxes going to the right, dashed lines signify fluxes going to the left, and contour spacing is $0.5 \mu \mathrm{g} \mathrm{m}^{-2} \mathrm{~s}^{-1}$. In Figure $4 \mathrm{c}$, solid lines signify updrafts, dashed lines signify downdrafts, and contour spacing is $0.5 \mathrm{~m} / \mathrm{s}$. In Figure $4 \mathrm{~d}$, solid lines represent southerly flows (from left to right), dashed lines represent northerly flows (from right to left), and contour spacing is 2 $\mathrm{m} / \mathrm{s}$; the shaded area is the visible cloud $\left(q_{c}>10^{-4} \mathrm{~g} / \mathrm{kg}\right)$.

pare the field of vertical velocity in Figure 4c). This can also be seen from Figures $3 \mathrm{a}$ and $4 \mathrm{a}$ which show the fields of the vertical fluxes of $\mathrm{SO}_{2}$ as an inert tracer for 45 and $55 \mathrm{~min}$. (The total maxima and minima of the flows encountered are sum- marized in Table 1.) The inflow and outflow at cloud base compensate around $60 \mathrm{~min}$, when the calculation was terminated. At that time the cloud has grown very big (length of cloud base $\sim 8 \mathrm{~km}$ ), but total liquid water content has de-

Table 1. Summary of the Main Cloud Characteristics and Minima and Maxima of Occurring Fluxes

\begin{tabular}{|c|c|c|c|c|c|c|c|}
\hline & \multicolumn{7}{|c|}{ Model Time, min } \\
\hline & 30 & 35 & 40 & 45 & 50 & 55 & 60 \\
\hline Cloud life time, $\min$ & 4 & 9 & 14 & 19 & 24 & 29 & 34 \\
\hline Height of cloud top, km & 1.4 & 2 & 3 & 3 & 3 & 2.8 & 2.6 \\
\hline Height of cloud base, $\mathbf{k m}$ & 0.8 & 0.8 & 0.8 & 0.6 & 0.6 & 0.4 & 0.4 \\
\hline$u_{\max / \min }, \mathrm{m} / \mathrm{s}$ & $7.0 /-5.1$ & $12.0 /-5.2$ & $12.1 /-7.6$ & $10.7 /-6.0$ & $10.0 /-6.6$ & $8.0 /-6.1$ & $7.5 /-5.5$ \\
\hline$w_{\max / \operatorname{man}}, \mathrm{m} / \mathrm{s}$ & $1.4 /-0.5$ & $11.6 /-5.9$ & $10.5 /-4.4$ & $5.8 /-3.5$ & $4 /-2.5$ & $4.4 /-3.0$ & $2.1 /-1.6$ \\
\hline$q_{c}, \mathrm{~g} / \mathrm{kg}$ & 0.2 & 1.9 & 3.2 & 1.8 & 1.2 & 0.8 & 1.0 \\
\hline$w_{L}, \mathrm{~g} / \mathrm{kg}$ & 0.2 & 2.0 & 6.0 & 3.9 & 3.3 & 1.7 & 1.3 \\
\hline $\begin{array}{l}F_{\mathrm{h}, S O 2, \max / \min } \\
\quad \text { (inert tracer), } \mu \mathrm{g} \mathrm{m}^{-2} \mathrm{~s}^{-1}\end{array}$ & $11.0 / 0$ & $16.3 /-7.8$ & $16.1 /-8.2$ & $9.4 /-4.6$ & $16.4 /-3.3$ & $14.5 /-3.1$ & $14.0 /-3.0$ \\
\hline $\begin{array}{l}F_{\mathrm{v}, \mathrm{SO} 2 \mathrm{max} / \mathrm{min}} \\
\quad \text { (inert tracer), } \mu \mathrm{g} \mathrm{m}^{-2} \mathrm{~s}^{-1}\end{array}$ & $2.9 /-0.4$ & $14.9 /-1.4$ & $7.6 /-2.3$ & $5.6 /-1.7$ & $4.5 /-4.6$ & $4.2 /-2.1$ & $3.4 /-1.8$ \\
\hline $\begin{array}{l}F_{\mathrm{h}, \mathrm{SO} 2, \max / \min } \\
\text { (oxidation), } \mu \mathrm{g} \mathrm{m}^{-2} \mathrm{~s}^{-1}\end{array}$ & $11.0 / 0$ & $16.3 /-7.8$ & $16.1 /-3.7$ & $9.4 /-2.5$ & $16.4 /-1.6$ & $14.5 /-1.5$ & $14.0 /-1.3$ \\
\hline $\begin{array}{l}F_{\mathrm{v}, \text { SO2,max/min }} \\
\text { (oxidation), } \mu \mathrm{g} \mathrm{m}^{-2} \mathrm{~s}^{-1}\end{array}$ & $2.9 /-0.4$ & $14.1 /-1.3$ & $6.0 /-1.5$ & $4.7 /-1.7$ & $4.4 /-4.6$ & $4.1 /-1.5$ & $3.3 /-1.2$ \\
\hline $\begin{array}{l}F_{\mathrm{h}, \mathrm{H} 2 \mathrm{O}, \max / \min } \\
\text { (oxidation), } \mu \mathrm{g} \mathrm{m}^{-2} \mathrm{~s}^{-1}\end{array}$ & $5.8 / 0$ & $8.6 /-4.1$ & $8.6 /-1.4$ & $5.0 /-1.0$ & $8.7 /-0.6$ & $8.1 /-0.5$ & $7.5 /-0.1$ \\
\hline $\begin{array}{l}F_{\mathrm{v}, \mathrm{H} 2 \mathrm{O} 2, \mathrm{max} / \mathrm{mun}} \\
\quad \text { (oxidation), } \mu \mathrm{g} \mathrm{m}^{-2} \mathrm{~s}^{-1}\end{array}$ & $1.6 /-0.2$ & $7.5 /-0.7$ & $3.2 /-0.5$ & $2.3 / 0.8$ & $2.2 /-2.6$ & $2.0 /-0.9$ & $1.1 /-0.5$ \\
\hline
\end{tabular}

Note that the maxima and minima pertain to the total model domain and not necessarily to a location in the studied cloud. 
creased (see Table 1) and the precipitation has almost ceased [Flossmann, 1991].

Figure $2 \mathrm{~b}$ shows the transport through cloud top where we can see that the mass transport of the gases through cloud top is a factor of 5-10 smaller than the transport through cloud base. This is caused by the fact that the vertical velocity at cloud top is generally small (see Figures $3 c$ and $4 c$ ). Until 42 min, this transport is zero. Then we note a small net loss due to an updraft at cloud top. After this, we have a net gain of mass due to a coexistence of weak updraft and downdraft regions at cloud top (Figures $3 \mathrm{c}$ and $4 \mathrm{c}$ ) whereby the downdrafts compensate the updrafts and reentrain previously detrained gas. We also note the presence of gas above cloud top in Figures 5 and 6 which give the gas concentrations at 45 and $55 \mathrm{~min}$. There we also see the strong influence of the uptake of
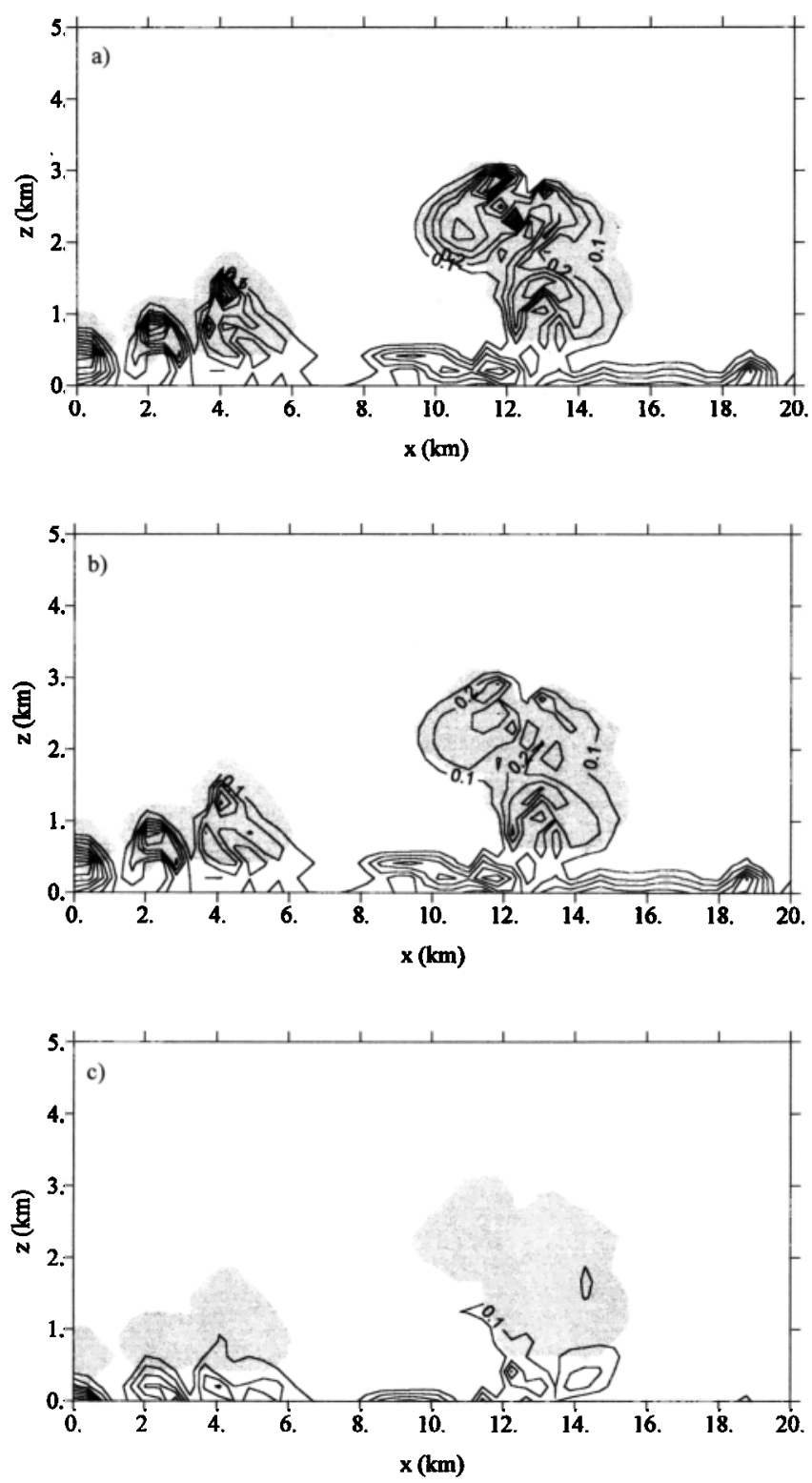

Figure 5. Gas concentration fields in the air in $\mathrm{ppb}(\mathrm{v})$ after $45 \mathrm{~min}$ of model time (19 min of cloud life time). (a) $\mathrm{SO}_{2}$ concentration from case 1 , (b) $\mathrm{SO}_{2}$ concentration from case 2 , (c) $\mathrm{H}_{2} \mathrm{O}_{2}$ concentration from case 2; contour spacing is 0.1 $\mathrm{ppb}(\mathrm{v})$; the shaded area is the visible cloud $\left(q_{c}>10^{-4} \mathrm{~g} / \mathrm{kg}\right)$.
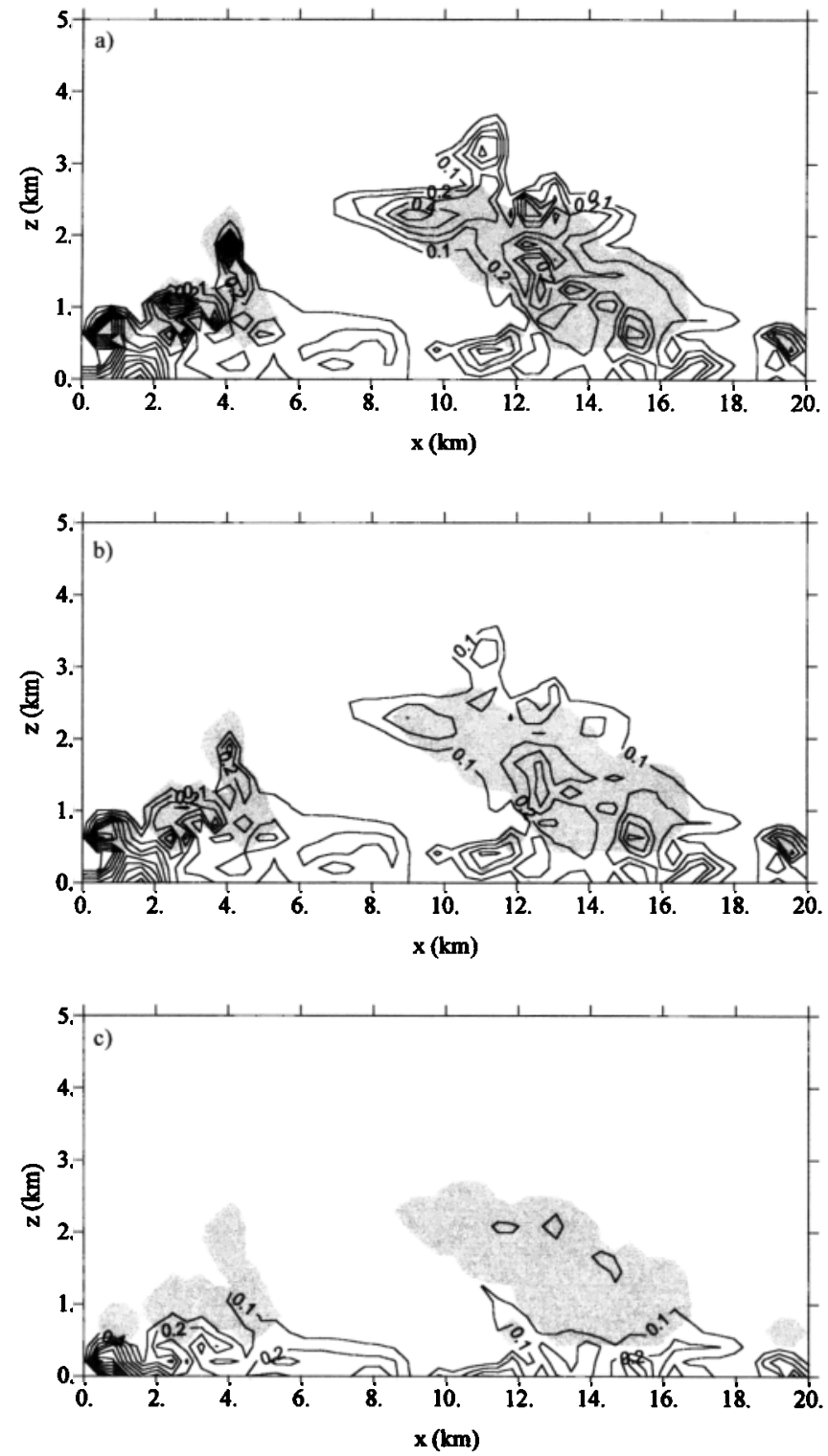

Figure 6. Gas concentration fields in the air in $\mathrm{ppb}(\mathrm{v})$ after 55 min of model time (29 min of cloud life time). (a) $\mathrm{SO}_{2}$ concentration from case 1 , (b) $\mathrm{SO}_{2}$ concentration from case 2 , (c) $\mathrm{H}_{2} \mathrm{O}_{2}$ concentration from case 2 ; contour spacing is 0.1 $\mathrm{ppb}(\mathrm{v})$; the shaded area is the visible cloud $\left(q_{c}>10^{-4} \mathrm{~g} / \mathrm{kg}\right)$.

the gas into the cloud and the subsequent reactions (note the changing aspect ratio and displayed domain as compared to Figures 3 and 4). Comparing Figures $5 \mathrm{a}$ and $5 \mathrm{~b}$ and $6 \mathrm{a}$ and $6 \mathrm{~b}$ we see the transport and uptake of $\mathrm{SO}_{2}$ by the cloud. Note the reduction in the boundary layer and the accumulation in the cloud regions. However, the resulting $\mathrm{SO}_{2}$ concentrations in the cloud are smaller in case 2 (scavenged gas) than case 1 (inert tracer) due to the scavenging of part of the $\mathrm{SO}_{2}$ into the liquid phase. This becomes even more prominent for $\mathrm{H}_{2} \mathrm{O}_{2}$. The high Henry's law constant is responsible for the fact that we see almost no $\mathrm{H}_{2} \mathrm{O}_{2}$ (concentrations below $0.01 \mathrm{ppb}(\mathrm{v})$ in the center of the cloud and concentrations below $0.1 \mathrm{ppb}(\mathrm{v})$ at the edges) above $1 \mathrm{~km}$. We find this effect also in the curves for the net mass transport (Figure 7). For the transport through cloud base (Figure 2a) we still see roughly a factor of 2-3 between $\mathrm{H}_{2} \mathrm{O}_{2}$ and $\mathrm{SO}_{2}$ maintained. The transport through 


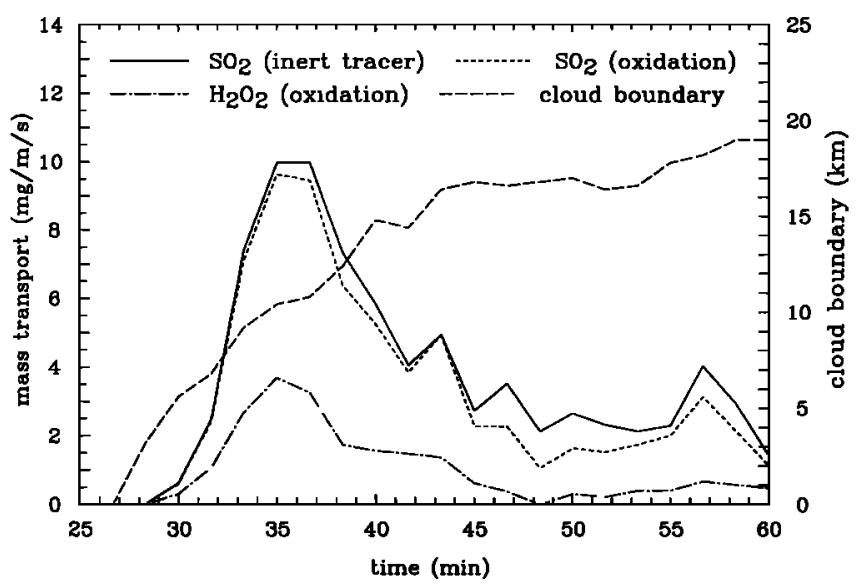

Figure 7. Net transport of mass in $\mathrm{mg} \mathrm{m}^{-1} \mathrm{~s}^{-1}$ into the cloud. The long-dashed line gives the length of the cloud boundary through which the transport occurred.

cloud top (Figure $2 \mathrm{~b}$ ), however, differs by roughly a factor of 8 as almost no $\mathrm{H}_{2} \mathrm{O}_{2}$ is found at cloud top.

Figures $2 \mathrm{c}$ and $2 \mathrm{~d}$ give the transport through the two lateral boundaries of the cloud which can be artificially identified in a 2-D simulation. In a simulation with no mesoscale horizontal wind, these two transports would be identical. In the present simulation, however, we have initialized the model with an observed southerly flow for the horizontal wind (from left to right in Figures 3-6 displayed by a solid line in Figures 3d and 4d) in the lower $2 \mathrm{~km}$ and a northerly flow in the upper part of the atmosphere. These flows were identified with some largerscale clusters around the small cell under consideration [Warner et al., 1979]. The flow is disturbed by circulations associated with this cloud which tends to develop two "rotors" (see, e.g., Figures 3c and 3d). The strength of the resulting horizontal fluxes depends on whether the horizontal flow of the cloud itself is in the same direction as the mesoscale flow or opposing it. Figure $2 \mathrm{c}$ shows the transport through the left boundary of the cloud. We see here in general an inflow, i.e., a positive contribution until $42 \mathrm{~min}$, resulting from the advection with the mesoscale flow. From 42 to $47 \mathrm{~min}$ the outflow part of the "cloud rotor" (see Figure $3 b$ ) dominates the transport as the cloud now extends well into the inversion with the northerly flow aloft (Figure 3d). After $45 \mathrm{~min}$, the circulation of the cell decreases (see Table 1) due to its decay. Furthermore, after $50 \mathrm{~min}$, the cloud top begins to subside, and consequently, that part of the cloud which extends into the northerly flow region decreases. Thus the inflow transport again dominates the outflow, and we have a net gain of mass. The transport through the right cloud boundary is smaller and always represents a net loss for the cloud as the horizontal flow field developed by the cloud at this side is acting all the time counteracting the large-scale flow (Figures 3d and 4d). As seen in Figures $3 b$ and $4 b$, almost no gain results from the inflow in the lowest kilometer as the horizontal inflow against the largescale flow is not sufficiently developed. We only see an outflow portion which is sufficiently strong because it is mainly located in the region between 1 and $2 \mathrm{~km}$ and thus goes in the same direction as the large-scale flow. It is responsible for the net loss of mass through the right cloud boundary. Above, the transport again is negligible. Combining the mass transport through all four boundaries, we can calculate a net budget for the cloud, displayed in Figure 7. We see here that the budget is mainly determined by the mass transport through cloud base (compare Figure 2a) as the transports through the sides and the top are generally much smaller and often compensate each other.

Figures 8 and 9 present a summary of the mass fluxes for 45 and $55 \mathrm{~min}$ as a function of height. Figures 8 and 9 are given to support later developments of parameterizations of the process of cloud venting for larger-scale models. Thus the positive and negative components of the fluxes were averaged separately and are displayed as separate curves. Again, we see that the qualitative behavior of all three gases is similar and only determined by their different solubility.

Looking at Figure $8 \mathrm{a}$ we see that the mean vertical fluxes for $\mathrm{SO}_{2}$ show a maximum shortly above cloud base, coupled to the maximum in vertical velocity (Figure $3 \mathrm{c}$ ). The maximum for $\mathrm{H}_{2} \mathrm{O}_{2}$ is much smaller and shifted toward cloud base due to its high solubility. The maximum mean downward flux for $\mathrm{SO}_{2}$ is found near cloud top, while for $\mathrm{H}_{2} \mathrm{O}_{2}$ the maximum mean
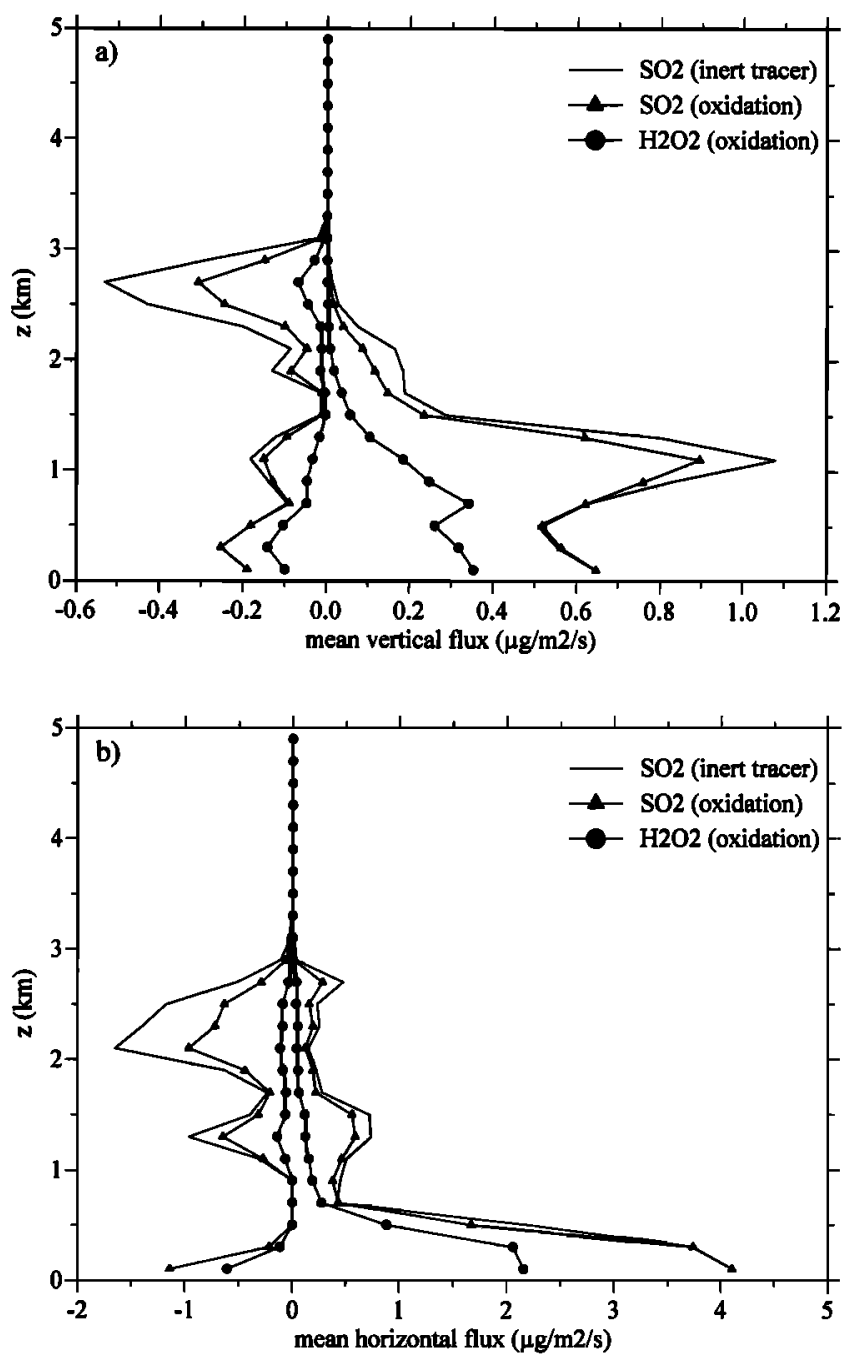

Figure 8. (a) Mean vertical flux and (b) horizontal flux in $\mu \mathrm{g}$ $\mathrm{m}^{-2} \mathrm{~s}^{-1}$ after $45 \mathrm{~min}$ of model time (19 min of cloud life time) for the three gases considered. In Figure $8 \mathrm{a}$, positive lines represent upgoing fluxes and negative lines downgoing fluxes. In Figure 8b, positive lines represent southerly fluxes (going to the right in Figures $3 b$ and $4 b$ ), and negative lines represent northerly fluxes (going to the left in Figures $3 \mathrm{~b}$ and $4 \mathrm{~b}$ ). 
downward flux is located below cloud base, again due to the high solubility of $\mathrm{H}_{2} \mathrm{O}_{2}$ in the cloud; $10 \mathrm{~min}$ later, at $55 \mathrm{~min}$ we see (Figure 9a) that the pattern for the vertical distribution of the mean fluxes has changed. In addition to a maximum below cloud base the upgoing mean vertical flux also shows a distinct maximum above cloud top, again correlated with the field of the vertical velocity (Figure 4c). In contrast to that, the downgoing mean flux shows its maximum inside the cloud.

The vertical distributions of the mean horizontal fluxes displayed in Figures $8 b$ and $9 b$ restate the observations made in Figures 2-4. We see that the strongest positive mean fluxes, representing a southerly flow, are found near the surface below cloud base as they are embedded into the southerly large-scale flow. The same applies to the negative mean fluxes, representing a northerly flow which is strongest between $2 \mathrm{~km}$ altitude and cloud top.

The total masses associated with the transport through the four different cloud boundaries and the net transport are given
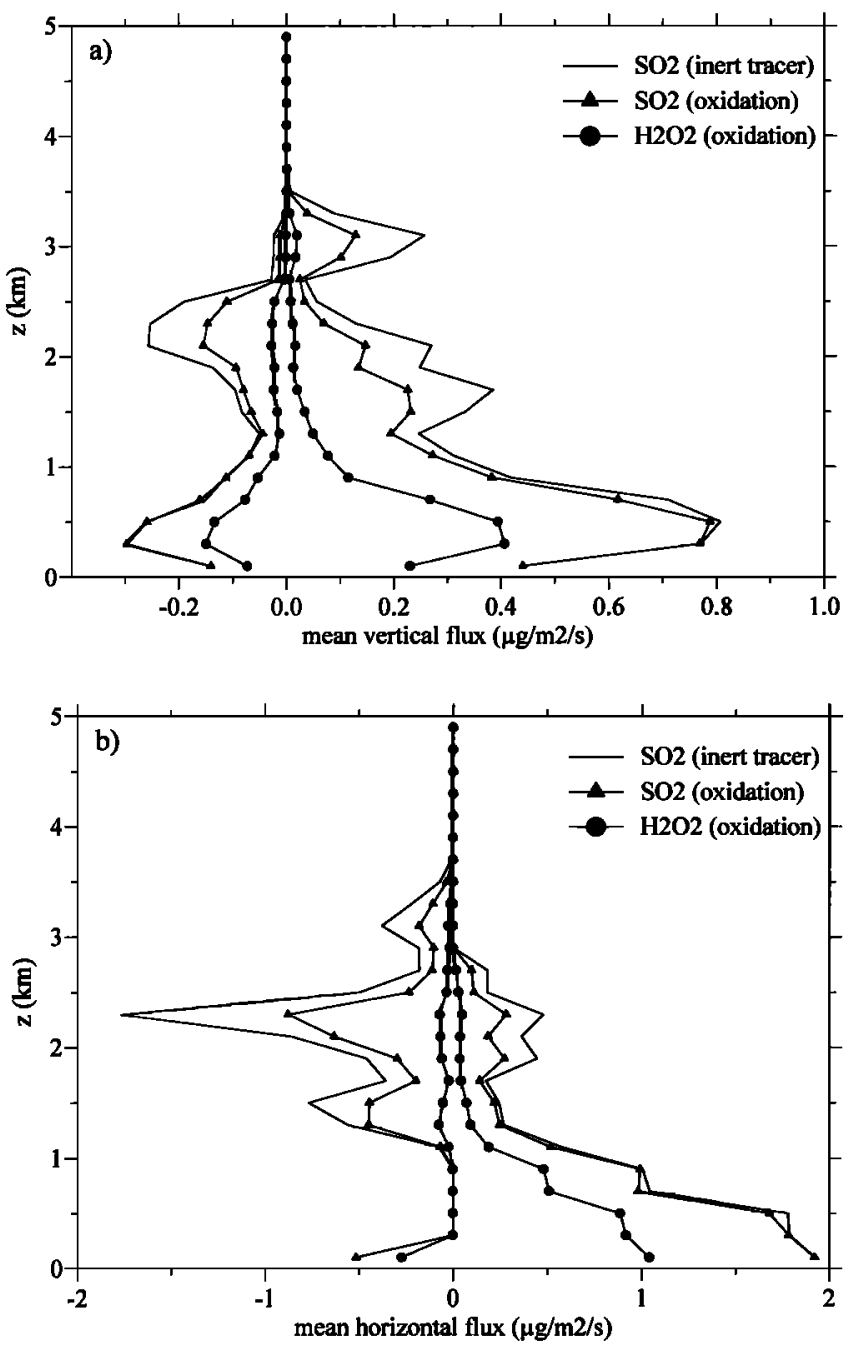

Figure 9. (a) Mean vertical flux and (b) horizontal flux in $\mu \mathrm{g}$ $\mathrm{m}^{-2} \mathrm{~s}^{-1}$ after $55 \mathrm{~min}$ of model time (29 min of cloud life time) for the three gases considered. In Figure $9 a$, positive lines represent upgoing fluxes, and negative lines represent downgoing fluxes. In Figure 9b, positive lines represent southerly fluxes (going to the right in Figures $3 b$ and $4 b$ ), and negative lines represent northerly fluxes (going to the left in Figures $3 b$ and $4 b)$.
Table 2. Total Masses Transported Through the 2-D Boundaries

\begin{tabular}{|c|c|c|c|}
\hline & $\begin{array}{c}\mathrm{SO}_{2} \\
\text { (Inert Tracer) }\end{array}$ & $\begin{array}{c}\mathrm{SO}_{2} \\
\text { (Oxidation) }\end{array}$ & $\begin{array}{c}\mathrm{H}_{2} \mathrm{O}_{2} \\
\text { (Oxidation) }\end{array}$ \\
\hline$T_{\text {claoud base, }}^{\text {total }}, \mathrm{g} / \mathrm{m}$ & 7.4 & 6.8 & 2.3 \\
\hline$T_{\text {cloud top }}^{\text {total }}, \mathrm{g} / \mathrm{m}$ & 1.0 & 0.6 & 0.1 \\
\hline$T_{\text {lcft boundary, }}^{\text {total }} \mathrm{g} / \mathrm{m}$ & 0.7 & 0.8 & 0.4 \\
\hline$T_{\text {rythl boundary, }}^{\text {total }} \mathrm{g} / \mathrm{m}$ & -1.3 & -1.3 & -0.7 \\
\hline$T^{\text {total }}(2-\mathrm{D}), \mathrm{g} / \mathrm{m}$ & 7.8 & 6.9 & 2.1 \\
\hline
\end{tabular}

in Table 2. These variables pertain to a $2-\mathrm{D}$ cloud with unit depth. Considering an average cloud base length of $5 \mathrm{~km}$ as explained in the section on analysis of the data (dimensions during the most active period, compare to Figure $2 \mathrm{a}$ ), we can estimate from Table 2 the total mass transfer of a 3-D cloud from the boundary layer to the free troposphere to be $37 \mathrm{~kg}$ for $\mathrm{SO}_{2}$ as an inert tracer, $34 \mathrm{~kg}$ for $\mathrm{SO}_{2}$ as a scavenged species, and $12 \mathrm{~kg}$ for $\mathrm{H}_{2} \mathrm{O}_{2}$. This corresponds to roughly $60 \%$ of the pollutant mass initially present in the boundary layer (this number depends on the size of the computational domain). However, not all this material will be found at a given time in the atmosphere. This will only apply to the case of the inert tracer. $\mathrm{SO}_{2}$ will be taken up into the cloud where it will be oxidized and transported to the surface with precipitation. Consequently, the fraction remaining in the atmosphere will vary but generally ranges around $75 \%$. As $\mathrm{H}_{2} \mathrm{O}_{2}$ has a much higher solubility, only about $30 \%$ of the material transported upward will actually be found in the atmosphere. The rest is scavenged rather efficiently by the cloud drops, whereby the scavenging is almost complete in the center of the cloud. Gaseous $\mathrm{H}_{2} \mathrm{O}_{2}$ can only be found at the cloud edges where the liquid water content is rather small.

\section{Summary and Conclusions}

We have used the DESCAM model in a 2-D dynamic framework. Assuming a local pollution layer of $\mathrm{SO}_{2}$ and $\mathrm{H}_{2} \mathrm{O}_{2}$ due to emission at the ground and an even mixture in a marine boundary layer of $400 \mathrm{~m}$, we have calculated the vertical and horizontal redistribution of these gases caused by a warm convective cloud. In order to cover the different solubilities of atmospheric gases we have performed two case studies. In the first case we have used $\mathrm{SO}_{2}$ as an inert tracer by artificially suppressing any uptake by the cloud drops. Even though this is an unrealistic scenario, it is nevertheless useful. First, as $\mathrm{SO}_{2}$ is not interacting with the cloud, it can be considered as a generic inert tracer so the results obtained would apply to any inert gas with similar distribution, taking into account the differences in molecular weight. Second, case 1 serves as a control for a comparison with the second case study where $\mathrm{SO}_{2}$ and $\mathrm{H}_{2} \mathrm{O}_{2}$ are scavenged by the cloud drops. In the cloud, S(4) is oxidized to $\mathrm{S}(6)$ with the help of $\mathrm{H}_{2} \mathrm{O}_{2}$ and $\mathrm{O}_{3}$ which are simultaneously present. The comparison between $\mathrm{SO}_{2}$ from case 1 (inert tracer) and case 2 (scavenged gas) gives information on the contribution of cloud chemistry to the process of cloud venting. Studying the vertical fluxes of the gases in the two cases, as well as the mass transport and the development of the vertical distribution of the gases, we can draw the following conclusions:

1. An inert tracer is depleted from the boundary layer and transported upward by a convective cloud. For the mediumsized warm cumulus cloud considered, $37 \mathrm{~kg}$ were transported 
through cloud base (initial MBL concentration of $1.4 \mu \mathrm{g} / \mathrm{m}^{3}$ ) corresponding to $60 \%$ of the initial pollutant mass in the MBL surrounding the cloud. Both the upward and downward fluxes at cloud top are at least a factor of 5 smaller than the inflow at cloud base. The transport through the sides is strongly influenced by the ambient mesoscale flow influencing cloud circulation.

2. The results showed little sensitivity to either using $\mathrm{SO}_{2}$ as an inert tracer or as a gas scavenged and oxidized by the cloud drops. The mass of $\mathrm{SO}_{2}$ transported through the cloud boundaries differs only marginally at cloud base. However, at cloud top the two cases differ by a factor of 2 , which reflects the integrated history of the $\mathrm{SO}_{2}$ uptake by the cloud. The total mass transport across cloud base introduces $34 \mathrm{~kg}$ of $\mathrm{SO}_{2}$ into the free troposphere which corresponds again to $60 \%$ of the $\mathrm{SO}_{2}$ mass initially present in the surrounding MBL. Owing to the uptake into the cloud drops, however, after half an hour of cloud life time only about $75 \%$ of the gas is actually in the air ready to participate in long range transport if the cloud would suddenly disappear. Part of the scavenged $\mathrm{SO}_{2}$ is present as $\mathrm{S}(6)$ in the cloud drops and part as S(4) which could eventually desorb again. Of this scavenged $\mathrm{SO}_{2}$ a certain fraction has already left the atmosphere because it has been redistributed through collision and coalescence into the large drops which have dropped to the surface as precipitation [cf. Flossmann, 1994].

3. As an example of a highly soluble gas, $\mathrm{H}_{2} \mathrm{O}_{2}$ was considered. Taking into account the fact that $0.5 \mathrm{ppb} \mathrm{H}_{2} \mathrm{O}_{2}$ results in a factor of 2 lower mass concentration than $\mathrm{SO}_{2}$ (MBL concentration $0.76 \mu \mathrm{g} / \mathrm{m}^{3}$ ), the mass transport of $\mathrm{H}_{2} \mathrm{O}_{2}$ across cloud base has the same magnitude as for $\mathrm{SO}_{2}$. Actually, about $12 \mathrm{~kg}(60 \%$ of the mass initially present in the surrounding MBL) were transported out of the boundary layer through a cloud base of roughly $25 \mathrm{~km}^{2}$ as compared to $34 \mathrm{~kg}$ for $\mathrm{SO}_{2}$. The fluxes through the other boundaries are rather small as almost all $\mathrm{H}_{2} \mathrm{O}_{2}(70 \%)$ was scavenged by the cloud drops and partly used up during the sulfur oxidation process.

4. The vertical distribution of the mean horizontal and vertical fluxes was studied. Here it was found that in general the vertical fluxes are strongest near cloud base and cloud top displaying a clear minimum in the middle of the cloud. The mean horizontal fluxes, however, are mainly determined by the ambient mesoscale flow.

A major shortcoming of this work is that the model in its present configuration is two-dimensional. Consequently, the estimates for 3-D clouds are simply extrapolations giving just the order of magnitude of the transport. We are presently working on an extension of the model to three dimensions.

These results presented pertain to a medium-sized cumulus cloud in the ITCZ. However, similar profiles of temperature and moisture are also found in larger areas of the subtropical and tropical oceans [Garret, 1992; Cotton and Anthes, 1989]. They also show a well-mixed layer at the surface of 400 to $600 \mathrm{~m}$ in depth and a weakly mixed layer above where the cloud forms. The cloud layer is then topped by the very dry and persistent trade wind inversion which will be found at a similar altitude to the transient inversion of GATE day 261. Consequently, the results obtained here can be applied to a very wide range of medium-sized cumuli and a rather large area. Even though the exchange in higher altitudes is limited in these latitudinal regions due to the persistent trade wind inversion, we can nevertheless speculate that through entering the trade winds the pollutants will be transported over much wider dis- tances than in the low mixed layer. Eventually, they might enter the ITCZ and be transported by the deep convection to even higher altitudes, emphasizing the climatic relevance of the cloud venting even by rather small clouds.

Acknowledgments. The authors acknowledge with gratitude the support by the European Community under EV5V-CT93-0313. They are solely responsible for the content of this manuscript. The authors thank William D. Hall for his support in installing the new version of the dynamical code and William R. Cotton for this help to improve the manuscript. The calculations for this paper have been done on the Cray C98 and C94 of the "Institut du Développement et des Ressources en Informatique Scientifique" (IDRIS, CNRS) in Orsay (France) under project 940180 . The authors acknowledge with gratitude the hours of computer time and the support provided. Furthermore, the authors acknowledge the support provided by the French national program PATOM.

\section{References}

Brümmer, B., Mass and energy budgets of a $1 \mathrm{~km}$ high atmospheric box over the GATE C-scale triangle during undisturbed and disturbed weather conditions. J. Atmos. Sci., 35, 997-1011, 1978.

Chatfield, R. B., and P. J. Crutzen, Sufur dioxide in remote oceanic air: Cloud transport of reactive precursors, J. Geophys. Res., 89, 7111$7132,1984$.

Ching, J., The role of convective clouds in venting ozone from the mixed layer, paper presented at 3rd Joint Conference on Application of Air Pollution Meteorology, Am. Meteorol. Soc., San Antonio, Tex., Jan. 12-15, 1982.

Clark, T. L., A small scale dynamic model using terrain-following coordinate transformation, $J$. Comput. Phys., 24, 186-215, 1977.

Clark, T. L., Numerical simulations with a three dimensional cloud model, J. Atmos. Sci., 36, 2191-2215, 1979.

Clark, T. L., and R. D. Farley, Severe downslope windstorm calculations in two and three spatial dimensions using anelastic interactive grid nesting, J. Atmos. Sci., 41, 329-350, 1984.

Clark, T. L., and R. Gall, Three dimensional numerical model simulations of air flow over mountainous terrain: A comparison with observation, Mon. Weather Rev., 110, 766-791, 1982.

Cotton, W. R., and R. A. Anthes, Storm and Cloud Dynamics, 883 pp., Academic, San Diego, Calif., 1989.

Cotton, W. R., G. D. Alexander, R. Hertenstein, R. L. Walko, R. L. McAnelly, and $M$. Nicholls, Cloud venting-A review and some new global annual estimates, Earth Sci. Rev., 39, 169-206, 1995.

Cuong, N. B., B. Bonsang, and G. Lambert, The atmospheric concentration of sulfur dioxide and sulfate aerosols over Antarctic, Subantarctic areas and oceans, Tellus, 26, 241-249, 1974.

Emanuel, K. A., Atmospheric Convection, 580 pp., Oxford Univ. Press, New York, 1994.

Ferek, R. J., R. B. Chatfield, and M. O. Andreae, Vertical distribution of dimethylsulfide in the marine atmosphere: Implications for the atmospheric sulfur cycle, Nature, 320, 514-516, 1986.

Flossmann, A. I., The scavenging of two different types of marine aerosol particles using a two-dimensional detailed cloud model, Tellus, Ser. $B, 43,301-321,1991$.

Flossmann, A. I., The effect of the impaction scavenging efficiency on the wet deposition by a convective warm cloud, Tellus, Ser. B, 45, 34-39, 1993.

Flossmann, A. I., A 2-D spectral model simulation of the scavenging of gaseous and particulate sulfate by a warm marine cloud, J. Atmos. Res., 32, 255-268, 1994.

Flossmann, A. I., and H. R. Pruppacher, A theoretical study of the wet removal of atmospheric pollutants, part III, J. Atmos. Sci., 45, 1857$1871,1988$.

Flossmann, A. I., W. D. Hall, and H. R. Pruppacher, A theoretical study of the wet removal of atmospheric pollutants, part I, J. Atmos. Sci., 42, 582-606, 1985.

Flossmann, A. I., H. R. Pruppacher, and J. H. Topalian, A theoretical study of the wet removal of atmospheric pollutants, part II, J. Atmos. Sci., 44, 2912-2923, 1987.

Garrat, J. R., The Atmospheric Boundary Layer, 316 pp., Cambridge Univ. Press, New York, 1992.

Hall, W. D., A detailed microphysical model within a two-dimensional 
dynamic framework: Model description and preliminary results, $J$. Atmos. Res., 37, 2486-2507, 1980.

Kok, G. L., Measurements of hydrogen peroxide in rainwater, Atmos. Environ., 14, 653-656, 1980.

Lelieveld, J., and P. J. Crutzen, Role of deep cloud convection in the ozone budget of the troposphere, Science, 264, 1759-1761, 1994.

Lilly, D. K. On the numerical simulation of buoyant convection, Tellus, 14, 148-172, 1962.

Nicholls, S., and M. A. LeMone, The fair weather boundary layer in GATE: The relationship of subcloud fluxes and structure to the distribution and enhancement of cumulus clouds, J. Atmos. Sci., 37, 2051-2067, 1980.

Seinfeld, J. H., Atmospheric Chemistry and Physics of Air Pollution, 738 pp., John Wiley, New York, 1986.

Smagorinsky, J., General circulation experiments with primitive equations, 1, Basic experiment, Mon. Weather Rev., 91, 99-164, 1963.

Warner, C., J. Simpson, D. W. Martin, D. Suchman, F. R. Mosher, and
R. F. Reinking, Shallow convection on day 261 of GATE: Mesoscale arcs, Mon. Weather Rev., 107, 1617-1635, 1979.

Winkler, Surface ozone over the Atlantic Ocean, J. Atmos. Chem., 7, 73-91, 1988

Wolff, G. T., M. S. Ruthkosky, D. P. Stroup, P. E. Korsog, M. A. Ferman, G. J. Wendel, and D. H. Stedman, Measurements of $\mathrm{SO}_{x}$, $\mathrm{NO}_{x}$ and aerosol species on Bermuda, Atmos. Environ., 20, 1229 $1239,1986$.

A. I. Flossmann and W. Wobrock, Laboratoire de Météorologie Physique, Université Blaise Pascal, CNRS, OPGC, 24 avenue des Landais, F-63177 Aubière Cedex, France. (e-mail: flossman@opgc.univbpclermont.fr; wobrock@opgc.univ-bpclermont.fr)

(Received August 22, 1995; revised May 6, 1996; accepted May 10, 1996.) 